\title{
A prospective survey of secondary care tooth wear referrals: demographics, reasons for concern and referral outcomes
}

IN BRIEF

- Investigates tooth wear referrals to secondary care.

- Provides insight into patients' perception of their tooth wear condition, their main concerns and expectations.

- Demonstrates an association between tooth wear and socioeconomic deprivation in patients.

\author{
K. E. Ahmed, ${ }^{* 1}$ C. A. Murray ${ }^{2}$ and C. J. Whitters ${ }^{3}$
}

Aim To provide a descriptive investigation of general dental practitioners' (GDPs) referrals to Glasgow Dental Hospital and School for management of tooth wear. Materials and methods One hundred and twenty-four patient-referrals were reviewed over a 12 month period. A questionnaire was also completed by patients and three reviewing consultants to identify patient demographics, patient perception, consultant's diagnosis and referral outcome. Results Overall survey return-rate was $67 \%$ of 124 included referrals. Males represented $72 \%$ of referrals compared to $28 \%$ for females $(p=0.001)$. A significant percentage of patients inhabited the most-deprived areas (59\%, $p=0.002)$. Sixty-one percent of patients were aware of their tooth wear within the past five years. Aesthetics was the primary concern for $54 \%$ of patients $(p=0.001)$. Attrition was the main aetiology of tooth wear in $51 \%$ of referrals $(p=0.001)$. Ninety-two percent of patients $(n=76 / 83)$ did not require specialist treatment and were consequently returned to their GDP, referred for hypnotherapy or reviewed later. Conclusion There was a significant association between social deprivation and tooth wear in GDP referrals to a secondary care dental facility. Males aware of their tooth wear for the preceding five years, presenting with appearance as their main complaint and displaying evidence of attrition were more likely to be referred by GDPs for specialist management or advice.

\section{INTRODUCTION}

Tooth wear, also referred to as tooth surface loss (TSL) or non-carious tooth surface loss (NCTSL), has been defined as pathological tooth tissue loss by a process other than dental caries. ${ }^{1}$ Tooth wear has a measurable impact on patient satisfaction in terms of appearance, pain levels, oral comfort, general performance, chewing and eating capacity. 2,3 The main aetiological factors of tooth wear are erosion, attrition and abrasion.

Dental erosion is tooth surface loss of enamel and/or dentine caused by chemical/ acid action from intrinsic, extrinsic and/or environmental factors not involving bacterial action. ${ }^{4,5}$ Dental erosion may arise from conditions including gastroesophageal reflux

\footnotetext{
'Clinical Academic Fellow, Clinical Dentistry Department, Restorative Dentistry Group, University of Glasgow Dental School, 378 Sauchiehall Street, Glasgow, G2 $3 \mathrm{JZ} ;{ }^{2}$ Professor of Restorative Dentistry, Department of Restorative Dentistry, Dubai School of Dental Medicine, Dubai Healthcare City, PO Box 505097, Dubai - U.A.E; ${ }^{3}$ Clinical Scientist/Honorary Lecturer, Department of Clinical Physics/Clinical Dentistry, Glasgow Dental Hospital and School, Glasgow, G2 3JZ

${ }^{*}$ Correspondence to: Khaled Ahmed

Email: KhaledAhmed@outlook.com
}

Online article number E9

Refereed Paper - accepted 11 December 2013

DOI: 10.1038/sj.bdj.2014.179

${ }^{\circ}$ British Dental Journal 2014; 216: E9 and eating disorders or from dietary factors such as a high intake of carbonated drinks, alcohol, fruit or fruit juice consumption. ${ }^{6-8}$ Attrition is caused by friction between opposing teeth and is frequently associated with para-functional temporomandibular or lingual habits. ${ }^{9}$ Such activities may include alone or in combination: jaw clenching, tooth grinding/bruxism, tooth tapping, cheek, lip or tongue biting, tongue thrusting, licking lips, tongue protrusion, gum chewing, object biting, hyper-salivation/swallowing or jaw posturing. ${ }^{10,11}$ Abrasion is the pathological wearing of dental hard tissue through mechanical forces by repeated introduction of foreign bodies into the oral cavity in contact with the dentition. ${ }^{12}$ There are a number of aetiological factors associated with abrasion with the most common relating to oral hygiene care, primarily tooth brushing and use of dentifrices. ${ }^{13,14}$ Abrasion may also occur due to certain habits such as pipe smoking, improper use of dental floss and toothpicks, chewing tobacco or biting pencils, pens and fingernails. ${ }^{15,16}$

The percentage of adults presenting with severe tooth wear has been confirmed to increase from $3 \%$ at the age of 20 to $17 \%$ at the age of 70 , thereby demonstrating a significant relationship with increasing age. ${ }^{17}$ The Adult Health Survey of 2009 estimated that $77 \%$ of dentate adults in England,
Wales and Northern Ireland demonstrated signs of tooth wear extending to dentine in their anterior teeth, with prevalence of tooth wear increasing with age. ${ }^{18}$ Several studies have demonstrated a relationship between gender and tooth wear. Indeed, males are associated with a higher prevalence of tooth wear compared to females. ${ }^{18-20}$

Studies investigating the association between socioeconomic status and tooth wear have mainly focused on dental erosion in children and adolescents. Those studies demonstrated a higher prevalence of dental erosion among patients from deprived socioeconomic groups when compared to less deprived cohorts. ${ }^{21-23}$ Moreover, children living in northern regions of the UK are twice as likely to suffer from dental erosion compared to those living in London and the South-East. ${ }^{24}$ In contrast, other studies have identified a higher prevalence of dental erosion in less deprived populations when compared to more deprived cohorts. ${ }^{25}$ Further investigation is needed to clarify the relationship between socioeconomic deprivation and tooth wear in adults and whether socioeconomic status can be considered as a risk factor in adults.

According to the General Dental Council (GDC), assessment and management of tooth wear falls under the provision of primary care, as outlined in the May 2011 published 
learning outcomes upon registration, (L.0 number 1.12.1). ${ }^{26}$ However, current tooth wear assessment regimes generally do not provide information as to whether the detected tooth wear is pathological and potentially requiring restorative intervention, or physiological as a natural result of age and requiring no clinical intervention. ${ }^{27}$ The treatment decision-making process is further complicated by lack of agreement upon acceptable thresholds in rates of tooth wear. ${ }^{28,29}$ This might explain limited availability of published studies related to rehabilitation of tooth wear that are of suitable scientific quality to be included within critical reviews and documented outcomes of various tooth wear rehabilitation approaches. ${ }^{30,31}$ Hence, with the lack of an evidence-based tooth wear management consensus, tooth wear management can become extremely challenging.

Nevertheless, recent technological advances in 3D imaging may potentially provide an objective quantitative means to measure tooth surface loss that rely on physical measurements rather than relying upon clinical subjective indices. ${ }^{32,33}$ This objective assessment of tooth wear is made possible through the rapid capture of 3D digitised images of a patient's dentition, whether directly in vivo or in vitro from dental casts.

The aim of this prospective survey was to provide a descriptive investigation of the patient cohort referred by general dental practitioners (GDPs) within Scotland to a secondary care setting for management of tooth wear and identify outcomes of the patient referral pathway. The survey would assist in identifying associations between certain patient factors, such as socioeconomic status, gender, age, aetiology of tooth wear, treatment needs, and their referral to secondary care and whether they can be considered as tooth wear risk factors that can aid clinicians in diagnosing and appropriately managing tooth wear. Furthermore, the referral outcome would assist in further developing current secondary care referral pathways through potential improvements to referral system and/or GDP awareness.

\section{MATERIALS AND METHODS}

A prospective survey study was undertaken at Glasgow Dental Hospital and School (GDH\&S) during 1 April 2010 to 30 April 2011. Ethical approval was provided by the West of Scotland Ethics Committee (10/S0709/59).

A tooth wear analysis questionnaire was formulated comprising three main sections (Appendix 1). Section A was completed

Table 1 Distribution of referred tooth wear patients within most deprived to least deprived categories, using SIMD quintiles based on patients' postcode data

\begin{tabular}{l|l}
\hline SIMD quintile & Number of referrals, $n=124$ \\
\hline 1 (most deprived) & $38(31 \%)$ \\
\hline 2 & $26(26 \%)$ \\
\hline 3 & $21(17 \%)$ \\
\hline 4 & $10(8 \%)$ \\
\hline 5 (least deprived) & $14(11 \%)$ \\
\hline Blank (information not given) & $15(12 \%)$
\end{tabular}

Table 2 Distribution of tooth wear referrals based on age groups.=

\begin{tabular}{|l|l|}
\hline Age group (years) & Number of referrals, $\mathrm{n}=124$ \\
\hline $19-30$ & $20(16 \%)$ \\
\hline $31-41$ & $31(25 \%)$ \\
\hline $42-52$ & $31(25 \%)$ \\
\hline $53-63$ & $27(22 \%)$ \\
\hline $64-79$ & $15(12 \%)$ \\
\hline
\end{tabular}

Table 3 Distribution of patient concerns when requesting a secondary care referral for their tooth wear

\begin{tabular}{l|l|l|l} 
Main reason of complaint & Males, $\mathrm{n}=57$ & Females, $\mathrm{n}=23$ & Total, $\mathrm{n}=80$ \\
\hline Aesthetics & $35(61 \%)$ & $8(35 \%)$ & $43(54 \%)$ \\
\hline Function & $10(18 \%)$ & 0 & $10(12 \%)$ \\
\hline Sensitivity & $7(12 \%)$ & $13(57 \%)$ & $20(25 \%)$ \\
\hline Other & $5(9 \%)$ & $2(9 \%)$ & $7(9 \%)$
\end{tabular}

Table 4 Tooth wear patient referral outcomes at GDH\&S

\begin{tabular}{l|l}
\hline Referral outcome & Number of referrals, $n=83$ \\
\hline Return to GDP & $39(47 \%)$ \\
\hline Hypnotherapy & $23(28 \%)$ \\
\hline Review & $14(17 \%)$ \\
\hline Secondary care treatment & $7(8 \%)$
\end{tabular}

by the screening auditor to collect patient demographic data and referral information. Section B was completed by the patient during their restorative specialist consultation and addressed patient-perception of their tooth wear condition. Section C was completed by the receiving consultant to record diagnosis and referral outcome. Only patients referred by GDPs solely for tooth wear management and assessment were included in this study. If there were other reasons for referral stated in the referral letter, then the patient was excluded from study participation. A convenience sample of 124 referrals was calculated for inclusion in the study during the 12 month time period. Included patients were reviewed by three restorative dentistry consultants at GDHES.

Before initial consultation, patient records were reviewed to identify patients referred by GDPs to GDHEtS for tooth wear management. Once tooth wear referrals were identified and Section A of the questionnaire completed, the study questionnaire was attached to patients' records and completed by the patient and receiving restorative consultant. Questionnaires were then collected at the end of each new patient consultation clinic for analysis.

In order to determine socioeconomic deprivation level of referred patients based upon the Scottish Index for Multiple 
Deprivation (SIMD) Scottish Health Board quintiles $^{34}$ the patient post-code data was recorded.

Statistical analysis was performed using SPSS $^{\text {тм }}$ (release 18.0.0) and MiniTab ${ }^{\text {тм }}$ (release 15.1.30.0.). In accordance with the determined sample size, a Fishers exact test was used to test differences between proportions.

\section{RESULTS}

One hundred and twenty-four patient referrals for tooth wear were identified and included in this pilot study. Eighty questionnaires were completed by patients for part B and 83 questionnaires completed by the reviewing consultant for part C. The over-all return rate of included tooth wear study referrals was $67 \%(\mathrm{n}=83)$.

There was a significant difference ( $p=0.001$ ) between the number of male and female patients referred for tooth wear management, with 72\% ( $\mathrm{n}=89$ ) of tooth wear referrals being male compared to $28 \%$ $(\mathrm{n}=35)$ female. A greater number of referred patients (59\%) inhabited the most deprived areas (quintiles one and two, according to the Scottish Index for Multiple Deprivation), this being significantly higher $(p=0.002)$ than those inhabiting the least deprived areas (Table 1). Attrition was mentioned as the underlying aetiological cause of tooth wear in $40 \%(n=50)$ of GDP referral letters, followed by erosion $(15 \% \mathrm{n}=18)$ and $10 \%(n=12)$ identifying a combination of attrition and erosion. There was no mention of the aetiological cause of tooth wear in 35\% ( $n=44)$ of GDP referral letters. In $90 \%$ ( $\mathrm{n}=121)$ of patient referrals, no dental study casts were sent with the GDP referral. Seventy-two percent of referred patients were between the ages of 31 and 63, which represented a significant difference $(p=0.001)$ when compared to other age groups (19-30 and 64-79) within the study (Table 2).

The percentage of patients previously aware of their tooth wear condition for less than six years was significantly higher $(\mathrm{p}=0.007, \mathrm{n}=49)$ at $61 \%$ compared to those aware of the condition for six to ten years ( $\mathrm{n}=17,21 \%)$ or over ten years $(\mathrm{n}=14$, $18 \%)$. The number of tooth wear patients either concerned or severely concerned by their tooth wear condition was significantly greater $(\mathrm{n}=71, \mathrm{p}=0.001)$ than those not concerned by the condition ( $\mathrm{n}=9,11 \%$,). Aesthetics was the principal reason for concern in 54\% of study patients (95\% C.I $=40-60 \%, p=0.001$ ) (Table 3). Fewer patients reported sensitivity or function as their main reasons for concern at 25\% and $12 \%$ respectively.
Attrition was diagnosed by restorative specialists as the primary aetiological cause of tooth wear in $51 \%$ of referrals $(n=42)$. This was significantly higher $(p=0.001)$ than tooth wear diagnosed as a result of erosion $(17 \%, n=14)$ or a combination of attrition and erosion (32\%, $n=27)$. Seventyeight patients, representing $92 \%$ of returned referral questionnaires, were assessed as not requiring specialist treatment intervention and were instead returned to their GDP with a treatment plan, referred for a course of hypnotherapy to address underlying bruxism behaviour or seen for further review within the secondary care setting to monitor tooth wear progression (Table 4).

\section{DISCUSSION}

The aims of this pilot study were to provide a descriptive investigation of a patient cohort referred by GDPs to a secondary care setting for management of tooth wear and determine outcomes of the patient referral pathway. The overall patient return rate of the survey was $67 \%$, which compares favourably to similar studies. ${ }^{35}$ Limited consultation time and patients not attending on the day of consultation contributed towards the varying return rates.

Thirty-five percent of GDP patient referral letters examined in this study did not record any underlying aetiological causes for the observed tooth wear. Furthermore, 98\% of referrals did not include diagnostic study casts that might potentially assist in identifying tooth wear progression over a given time period and presenting the receiving specialist with a baseline comparison.

The findings of this study demonstrate that referred tooth wear patients within this Scottish sub-population were more likely to be young to middle-aged males inhabiting socioeconomically deprived areas who were concerned by their tooth wear condition for which aesthetics was their main reason for concern. These findings are comparable to other studies investigating different geographical populations where males predominated GDP tooth wear referrals, aesthetics was the primary presenting complaint and socioeconomic deprivation and age were directly associated with tooth wear. ${ }^{2,17,18,36}$

An understanding of the demographics and needs of tooth wear patients will assist in delivering the appropriate care that these patients require and seek. Furthermore, identifying the various factors associated with tooth wear, such as bruxism, aesthetic concerns and socioeconomic deprivation, will help towards diagnosing and managing other underlying disorders that might be concomitant with tooth wear, such as stress, depression, eating disorders, alcohol and drug dependencies. ${ }^{37}$ Indeed, in this study we identified a predominance of patients originating from lower socioeconomic groupings within the tooth wear referral cohort. This is of particular relevance to the population involved in this study as Glasgow suffers from a 30\% increased rate of premature deaths compared to cities of similar socioeconomic deprivation distribution in the UK and more than half the excess deaths occurring in males under the age of 65 are directly related to alcohol and drugs. ${ }^{38}$

Referral to secondary care can be considered as part of the overall management process of tooth wear, through provision of a treatment plan or specialist clinical management of severe/advanced tooth wear cases. Interestingly, a substantial majority (92\%) of referred tooth wear patients were identified as not requiring clinical specialist treatment. These findings tend to raise questions with regard to the extent of tooth wear management in primary care. Furthermore, the lack of mention of a diagnosed aetiological cause and lack of inclusion of study casts of the patient's dentition at an earlier time point might divest reviewing consultants of valuable diagnostic data. These findings imply a need for increased awareness among primary dental care providers with regard to management of tooth wear, which can be provided through continued professional development.

In order to further improve secondary care provision for tooth wear patients, a more specific tooth wear referral system needs to be implemented. This referral system needs to ensure the inclusion of the diagnosed, underlying aetiological factor(s) of the observed tooth wear and the patient's principal reason of concern contributing towards the referral. Furthermore, the referral letter should also mention any previous tooth wear management attempts carried out by the referring GDP, such as dietary advice, splint therapy, oral hygiene advice and/ or composite build-ups. Dental casts taken previously can be sent with the referral letter or presented by the patient on the day of consultation, as this would present a baseline comparison to the patient's current dentition.

\section{CONCLUSION}

Based on the findings of this study, patients referred by general dental practitioners to Glasgow Dental Hospital and School for management of tooth wear are more likely to be males between the ages of 31-63 and inhabiting a socioeconomically deprived area. Generally, patients were aware of their tooth wear condition within the preceding 
five years and were either concerned or severely concerned by their condition with dental aesthetics being identified as the primary cause of concern. Attrition was determined to be the primary cause of tooth wear and the majority of referred patients did not require specialist intervention. The majority of tooth wear cases were returned to the referring dental practitioner with a treatment plan, referred for a course of hypnotherapy treatment or reviewed by a specialist for monitoring of tooth wear progression. Moreover, these findings highlight the need for increased awareness in primary dental care with regard to tooth wear management and development of current referral system in secondary dental care.

The authors declare that there was no conflict of interest present at the time of the undertaking of this study.

1. Eccles $J D$. Erosion affecting the palatal surfaces of upper anterior teeth in young people. A report of 19 cases. Br Dent J 1982; 152: 375-378.

2. Al-Omiri M K, Lamey P J, Clifford T. Impact of tooth wear on daily living. Int J Prosthodont 2006; 19: 601-605.

3. Bartlett D, Preiskel A, Shah P, Ahmed A, Moazzez R. An audit of prosthodontics undertaken in general dental practice in the South East of England. Br Dent J 2009; 207: 336.

4. Eccles J D. Dental erosion of non-industrial origin A clinical survey and classification. J Prosthet Dent 1979; 42: 649-653.

5. Bartlett D. Etiology and prevention of acid erosion. Compend Contin Educ Dent 2009: 30: 616-620.

6. Bartlett D. Intrinsic causes of erosion. Monogr Oral Sci 2006; 20: 119-139.

7. Cochrane N J, Cai F Yuan Y, Reynolds E C. Erosive potential of beverages sold in Australian schools. Aust Dent J 2009; 54: 238-244.

8. Holbrook W P, Furuholm J, Gudmundsson K Theodours A, Meurman J H. Gastric reflux is a significant causative factor of tooth erosion. J Dent Res 2009; 88: 422-426.

9. Van't Spijker A, Kreulen C M, Creugers N H. Attrition, occlusion, (dys)function, and intervention: a systematic review. Clin Oral Implants Res 2007; 18(Suppl 3): $117-126$.

10. Winocur $E$, Gavish A, Finkelshtein $T$, Halachmi M Gazit E. Oral habits among adolescent girls and their association with symptoms of temporomandibular disorders. J Oral Rehabil 2001; 28: 624-629.

11. Lavigne G J, Khoury S, Abe S, Yamaguchi T, Raphael K. Bruxism physiology and pathology: an overview for clinicians. J Oral Rehabil 2008; 35: 476-494.

12. Levitch L C, Bader J D, Shugars D A, Heymann H O. Non-carious cervical lesions J Dent 1994; 22: 195-207.

13. De Boer P, Duinkerke A S, Arends J. Influence of tooth paste particle size and tooth brush stiffness on dentine abrasion in vitro. Caries Res 1985; 19: 232-239.

14. Macdonald E, North A, Maggio B et al. Clinical study investigating abrasive effects of three toothpastes and water in an in situ model. J Dent 2010; 38: 509-516

15. Faulkner K D. Bruxism: a review of the literature. Part I. Aust Dent J 1990; 35: 266-276.

16. Gupta B N. Occupational diseases of teeth. J Soc Occup Med. 1990; 40: 149-152.

17. Van't Spijker A, Rodriguez J M, Kreulen C M, Bronkhorst E M, Bartlett D W, Creugers N H. Prevalence of tooth wear in adults. Int J Prosthodont 2009; 22: 35-42.

18. Health and Social Care Information Centre. Disease and related disorders - a report from the Adult Dental Health Survey 2009. London: HSCIC, 2011. Online report available at http://www.hscic.gov.uk/ catalogue/PUB01086 (accessed January 2014).

19. Dugmore $C R$, Rock W P. The prevalence of tooth erosion in 12-year-old children. Br Dent J 2004; 196: 279-282

20. Cunha-Cruz J, Pashova H, Packard J D, Zhou L M, Hilton T J, Nw P. Tooth wear: prevalence and associated factors in general practice patients. Community Dent Oral 2010; 38: 228-234.

21. Milosevic A, Young P J, Lennon M A. The prevalence of tooth wear in 14-year-old school children in Liverpool. Community Dent Health 1994; 11: 83-86.

22. De Carvalho Sales-Peres S H, Goya S et al. Prevalence of dental wear among 12-year-old Brazilian adolescents using a modification of the tooth wear index. Public Health 2008; 122: 942-948.

23. El Aidi H, Bronkhorst E M, Truin G J. A longitudinal study of tooth erosion in adolescents. J Dent Res 2008; 87: 731-735.

24. Nunn J H, Gordon P H, Morris A J, Pine C M, Walker
A. Dental erosion--changing prevalence? A review of British National childrens' surveys. Int J Paediatr Dent 2003; 13: 98-105.

25. Millward A, Shaw L, Smith A. Dental erosion in 4-year-old children from differing socio-economic backgrounds. J Dent Child 1994; 61: 263-266.

26. General Dental Council. Dental team learning out comes for registration. London: GDC, 2011. Online information available at http://www.gdc-uk.org/ newsandpublications/publications/Pages/default. aspx (accessed January 2014).

27. Young A, Amaechi B T, Dugmore C, Holbrook P, Nunn J, Schiffner U et al. Current erosion indices-flawed or valid? Summary. Clin Oral Investig 2008; 12(Suppl 1): S59-63.

28. Bartlett D, Dugmore C. Pathological or physiological erosion-is there a relationship to age? Clin Oral Investig 2008; 12(Suppl 1): S27-31.

29. Ganss C. How valid are current diagnostic criteria for dental erosion? Clin Oral Investig 2008; 12(Suppl 1): S41-49.

30. Johansson A, Johansson A K, Omar R, Carlsson G E. Rehabilitation of the worn dentition. J Oral Rehabil 2008; 35: 548-566.

31. Sabahipour L, Bartlett D. A questionnaire based study to investigate the variations in the management of tooth wear by UK and prosthodontists from other countries. Eur J Prosthodont Restor Dent 2009; 17: 61-66.

32. Keating A P, Knox J, Bibb R, Zhurov A I. A comparison of plaster, digital and reconstructed study model accuracy. J Orthod 2008; 35: 191-201.

33. Palaniappan $S$, Bharadwaj D, Mattar D L, Peumans $M$, Van Meerbeek B, Lambrechts P. Three-year randomized clinical trial to evaluate the clinical performance and wear of a nanocomposite versus a hybrid composite. Dent Mater 2009; 25: 1302-1314.

34. Scottish Index for Multiple Deprivation. Scottish Index for Multiple Deprivation 2012. Online information available $h$ ttp://simd.scotland.gov.uk/publication-2012/ (accessed January 2014).

35. Bartlett D W, Palmer I, Shah P. An audit of study casts used to monitor tooth wear in general practice. Br Dent J 2005; 199: 143-145.

36. Wazani B E, Dodd M N, Milosevic A. The signs and symptoms of tooth wear in a referred group of patients. Br Dent J 2012; 213: E10-E.

37. Ahmed K E. The psychology of tooth wear. Spec Care Dentist 2013; 33: 28-34.

38. Walsh $\mathrm{D}$, Bendel $\mathrm{N}$, Jones $\mathrm{R}$, Hanlon P. It's not 'just deprivation': Why do equally deprived UK cities experience different health outcomes? Public Health 2010; 124: 487-495. 
Appendix 1 Tooth wear questionnaire.

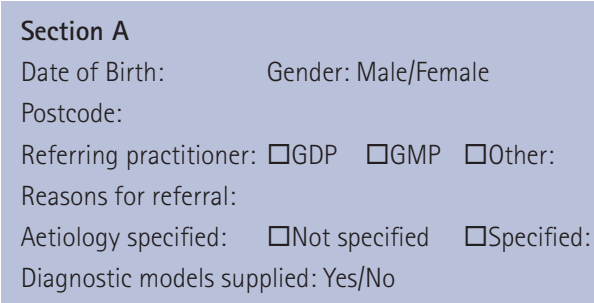

Section B (to be completed by patient)

Patient aware of condition: Yes/No

If 'Yes', how long has the patient been aware of the condition?

$\square<1$ year $\quad \square 1-5$ years $\quad \square 6-10$ years $\quad \square>10$ years

If 'Yes', is the patient concerned about their condition?

$\begin{array}{llllllllll}1 & 2 & 3 & 4 & 5 & 6 & 7 & 8 & 9 & 10\end{array}$

1: Not concerned 5: Concerned 10: Severely concerned

If 'Yes', main reason for concern:

$\square$ Aesthetics $\quad \square$ Sensitivity/Pain $\quad \square$ Function/Mastication $\quad \square$ Speech $\quad \square$ Other, please specify:

Section C (to be filled by clinician)

Clinician's diagnosis (Aetiology):

Referral outcome:

口Undergraduate clinic

$\square$ Consultant clinic

$\square \mathrm{SHO}$

$\square \mathrm{SpR} / \mathrm{SpT}$

$\square$ Hypnotherapy clinic

$\square$ Review

$\square$ Dentist with special interest

$\square$ Return to GDP

$\square$ Other, please specify 